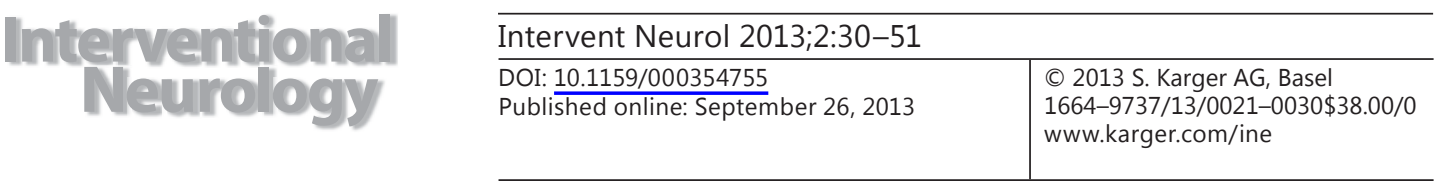

\title{
Current Options for the Management of Aneurysmal Subarachnoid Hemorrhage-Induced Cerebral Vasospasm: A Comprehensive Review of the Literature
}

\author{
Guilherme Dabus $^{a} \quad$ Raul G. Nogueira ${ }^{b}$ \\ a Department of Interventional Neuroradiology, Baptist Cardiac and Vascular Institute and \\ Baptist Neuroscience Center, Miami, Fla., and ${ }^{b}$ Departments of Neurology, Neurosurgery and \\ Radiology, Emory University School of Medicine, Marcus Stroke and Neuroscience Center, \\ Grady Memorial Hospital, Atlanta, Ga., USA
}

\section{Key Words}

Subarachnoid hemorrhage $\cdot$ Vasospasm · Delayed cerebral ischemia $\cdot$ Endovascular treatment $\cdot$ Angioplasty $\cdot$ Intra-arterial drug infusion

\begin{abstract}
Objectives: Cerebral vasospasm is one of the leading causes of morbi-mortality following aneurysmal subarachnoid hemorrhage. The aim of this article is to discuss the current status of vasospasm therapy with emphasis on endovascular treatment. Methods: A comprehensive review of the literature obtained by a PubMed search. The most relevant articles related to medical, endovascular and alternative therapies were selected for discussion. Results: Current accepted medical options include the oral nimodipine and 'triple- $\mathrm{H}$ ' therapy (hypertension, hypervolemia and hemodilution). Nimodipine remains the only modality proven to reduce the incidence of infarction. Although widely used, 'triple- $\mathrm{H}$ ' therapy has not been demonstrated to significantly change overall outcome after cerebral vasospasm. Indeed, both induced hypervolemia and hemodilution may have deleterious effects, and more recent physiologic data favor normovolemia with induced hypertension or optimization of cardiac output. Endovascular options include percutaneous transluminal balloon angioplasty (PTA) and intra-arterial (IA) infusion of vasodilators. Multiple case reports and case series have been encountered in the literature using different drug regimens with diverse mechanisms of action. Compared with PTA, IA drug infusion has the advantages of distal penetration and a better safety profile. Its main disadvantages are the more frequent need for repeat treatments and its systemic hemodynamic repercussions. Alternative options using intraventricular/cisternal drug therapy and flow augmentation strategies have also shown possible benefits; however, their use is not yet as well established. Conclusion: Blood pressure or cardiac output optimization should be
\end{abstract}


the mainstay of hyperdynamic therapy. Endovascular treatment appears to have a positive impact on neurological outcome compared with the natural history of the disease. The role of intraventricular therapy and flow augmentation strategies in association with medical and endovascular treatment may, in the future, play a growing role in the management of patients with severe refractory vasospasm.

(C) 2013 S. Karger AG, Basel

\section{Introduction}

Cerebral vasospasm is a delayed and self-limited condition that may occur when cerebral vessels are exposed to blood in the subarachnoid space (subarachnoid hemorrhage, SAH), usually after aneurysmal rupture. It typically occurs 4-14 days after the SAH, with a peak incidence between 6 and 10 days. Given that the vast majority of intracranial aneurysms are located in the circle of Willis, the large proximal vessels are the ones most frequently affected by vasospasm. The volume, density and prolonged presence of subarachnoid blood are important predictors of vasospasm [1,2]. The concept of cerebral vasospasm after SAH was first introduced in 1951 by Ecker and Riemenschneider [3]. Along with the intravascular volume depletion and impaired cerebral autoregulation commonly seen after aneurysmal $\mathrm{SAH}(\mathrm{aSAH})$, vasospasm contributes to decreasing cerebral blood flow (CBF), resulting in delayed ischemic injury. Indeed, vasospasm constitutes one of the most common treatable causes of morbidity and mortality following aSAH. Approximately $70 \%$ of aSAH patients will demonstrate angiographic evidence of vasospasm; however, only $40 \%$ will have clinical symptoms, and approximately $30 \%$ will have delayed ischemic injury. Up to $20 \%$ of patients will die or have severe deficits as a result of vasospasm [1, 2, 4-28].

\section{Pathological Findings in SAH-Induced Cerebral Vasospasm}

In the setting of SAH, the term 'vasospasm' implies a complex condition that evolves way beyond the simple constriction of the pial vessels. Pathological specimens have demonstrated smooth muscle and myofibroblast proliferation with cellular necrosis and remodeling. Intimal hyperplasia, collagen deposition and fibrosis have also been described. In addition, intraluminal platelet aggregation with microthrombus formation, arterial thrombosis and distal embolization may be encountered [29-32].

\section{Medical Therapy in SAH-Induced Cerebral Vasospasm}

The primary aim of prophylactic and therapeutic vasospasm management is to optimize $\mathrm{CBF}$ in order to prevent delayed cerebral ischemia. Current accepted options include the oral calcium channel blocker nimodipine and hyperdynamic therapy.

'Triple-H' Therapy and the Novel Concepts of Hyperdynamic Therapy

Although widely used, 'triple-H' therapy (hypertension, hypervolemia and hemodilution) has not yet been demonstrated to significantly change the overall prognosis for cerebral vasospasm. Moreover, there is no good evidence from randomized controlled studies of a benefit of 'triple-H' or its separate components to support any improvement in either CBF or clinical outcomes in SAH patients [33, 34]. Egge et al. [35] randomized 32 aSAH patients to receive either normovolemia $(\mathrm{n}=16)$, defined as neutral fluid balance without any hypertensive 
therapy, or 'triple-H' therapy ( $\mathrm{n}=16)$, defined as a central venous pressure (CVP) goal of 8-12 $\mathrm{cm}_{2} \mathrm{O}$, a venous hematocrit of $30-35 \%$, and a mean arterial pressure (MAP) $>20 \mathrm{~mm} \mathrm{Hg}$ higher than preoperative values. Significant differences were achieved for MAP, CVP and hematocrit. There were no differences in the incidence of clinical or transcranial Doppler (TCD) vasospasm, CBF (SPECT) measurements, or long-term outcomes (Glasgow Outcome Scale score at 1 year) between the two groups. However, the hospitalization costs were higher and complications were more frequent for the 'triple- $\mathrm{H}$ ' therapy group.

\section{Hypervolemia}

In a small randomized controlled trial, Lennihan et al. [36] randomly assigned 82 patients to receive isotonic crystalloid and $5 \%$ albumin solution every $2 \mathrm{~h}$ to maintain either normal $(n=41)$ or elevated $(n=41)$ cardiac filling pressures from the day after aneurysm clipping until SAH day 14. CBF ( ${ }^{133} \mathrm{Xe}$ clearance) was measured before randomization and approximately every 3 days thereafter. There was no difference in mean global CBF or minimum regional CBF between the two treatment groups. Symptomatic vasospasm occurred in $20 \%$ of the patients in each group. The authors concluded that prophylactic hypervolemia therapy is unlikely to confer an additional benefit over euvolemia [36]. More recent data also suggest that induced hypervolemia is an ineffective approach and may actually be detrimental $[34,35,37]$.

\section{Hemodilution}

Despite the theoretical advantages related to its beneficial rheologic effect on $\mathrm{CBF}$, hemodilution appears to be detrimental and has been shown to reduce oxygen delivery capacity and increase the volume of ischemic areas in the brain [38]. Conversely, higher hemoglobin levels have been shown to be associated with decreased rates of cerebral infarction, poor outcome and death after SAH [39]. Notably, blood transfusion has been associated with increased rates of angiographic vasospasm, cerebral ischemia and worse functional outcomes in SAH patients $[39,40]$.

\section{Hypertension}

Raabe et al. [41] performed a retrospective review of 45 patients with periods of hypervolemia, moderate induced hypertension or aggressive hypervolemic hypertension. Hypervolemia was associated with increase in brain oxygenation during 3/25 intervals (12\%) and complications in 9 patients (53\%). Aggressive hypervolemic hypertension was associated with increase in brain oxygenation during 6/10 intervals (60\%) and complications in 5 patients $(50 \%)$. Moderate induced hypertension was associated with increase in brain oxygenation in $50 / 55$ periods (90\%), with complications occurring in 3 patients (8\%) [41]. Muench et al. [42] performed a prospective observational study on 10 Fisher III SAH patients treated with surgical clipping for anterior circulation aneurysms. Patients with heart failure, electrocardiogram abnormalities, pulmonary complications and renal insufficiency were excluded. The patients received external ventriculostomy and microprobes to measure subcortical regional $\mathrm{CBF}$ and brain tissue oxygenation into the vascular territory at risk for developing vasospasm. Stable xenon CT was performed to validate the regional CBF measurements. Vasospasm was screened by TCD and confirmed by xenon CT and angiography. Induced hypertension and hypervolemia had a statistically significant impact on intracranial pressure (ICP). However, ICP elevation was clinically not relevant, since it could be treated by cerebrospinal fluid (CSF) drainage. Cerebral perfusion pressure increased as MAP was elevated by vasopressors. Significant increases in CBF were seen with both normovolemic induced hypertension and 'triple- $\mathrm{H}^{\text {', }}$ but not with hypervolemic hemodilution. However, patients undergoing normovolemic induced hypertension were the only ones to show a significant increase in brain tissue oxygenation [42]. These data suggest that moderate hypertension (cerebral perfusion pressure 
$80-120 \mathrm{~mm} \mathrm{Hg}$ ) in a normovolemic patient is an effective method of improving cerebral oxygenation and is associated with a lower complication rate as compared with hypervolemia or aggressive hypervolemic hypertensive therapy. Notably, the prophylactic use of induced hypertension has been associated with development of vasospasm in SAH patients [43]. Therefore, induced hypertension should probably only be instituted once the diagnosis of vasospasm has been made by clinical, sonographic or imaging criteria.

\section{Cardiac Output Augmentation}

Cardiac output optimization with dobutamine has been shown to reverse flow deficits from SAH-induced vasospasm independent of blood pressure, and this approach may be safer and better tolerated than induced hypervolemia or pharmacological blood pressure augmentation with phenylephrine. Joseph et al. [44] studied 16 patients with SAH-induced vasospasm who were treated with hypervolemia, phenylephrine to increase MAP, or dobutamine to increase cardiac output. Only one variable (CVP, MAP or cardiac output) was manipulated in each patient. Direct CBF measurements were obtained by xenon CT before and after treatment. Phenylephrine was associated with an increase in mean MAP from 102.4 to 132.1 $\mathrm{mm} \mathrm{Hg}$ and an increase in mean CBF in the vasospasm area from 19.2 to $33.7 \mathrm{ml} / 100 \mathrm{~g} / \mathrm{min}$. Dobutamine was associated with an increase in mean cardiac index from 4.1 to $6.0 \mathrm{l} / \mathrm{min} / \mathrm{m}^{2}$ and an increase in mean CBF in the vasospasm area from 24.8 to $35.4 \mathrm{ml} / 100 \mathrm{~g} / \mathrm{min}$. Hypervolemia was associated with an increase in mean CVP from 5.4 to $7.3 \mathrm{~cm} \mathrm{H}_{2} \mathrm{O}$ and no changes in mean CBF [44]. Kim et al. [45] retrospectively compared $174 \mathrm{SAH}$ patients treated with hypervolemia (CVP goal: >8 mm Hg) and hypertension (MAP goal: 110-130 mm Hg) with 279 patients treated with normovolemic (wedge pressure: $10-14 \mathrm{~mm} \mathrm{Hg}$ ) optimization of cardiac output (index: $>4.5 \mathrm{l} / \mathrm{min} / \mathrm{m}^{2}$ ) and moderate blood pressure elevation (MAP >100 mm $\mathrm{Hg}$ ). Statistically significantly lower rates of pulmonary edema (14 vs. 6\%), sepsis (14 vs. 6\%) and mortality (34 vs. 29\%) were seen in the cardiac output augmentation group [45].

In summary, 'triple- $\mathrm{H}$ ' therapy is associated with significant risks including cardiac failure, electrolyte abnormalities, cerebral edema, bleeding diathesis from dilution of clotting factors, and other unknown risks such as the potential rupture of unsecured unruptured aneurysms. Therefore, prophylactic hemodynamic therapy needs further study before it can be routinely advocated [46]. There is a paucity of well-designed studies regarding the safety and efficacy of hyperdynamic therapy, but emerging physiologic data suggest that the institution of normovolemic induced hypertension or cardiac output augmentation while avoiding hypervolemic hemodilution may be the best and safest approach to increase CBF after SAH [34].

\section{Pharmacological Therapy}

Nimodipine is the only treatment modality that has been shown systematically to improve outcome in aSAH patients. However, oral nimodipine only reduces the incidence of vasospasm-induced cerebral infarction by $34 \%$ and the rate of poor outcomes in aSAH by $40 \%$ [47]. A randomized trial has shown that continuous intravenous infusion of high-dose nicardipine $(0.15 \mathrm{mg} / \mathrm{kg} / \mathrm{h})$ significantly decreases the incidence of symptomatic, angiographic and TCD vasospasm. However, the overall efficacy of this regimen has been limited by prolonged hypotension, pulmonary edema and renal dysfunction, and a positive impact on SAH outcomes could not be established [48]. A subsequent randomized trial showed that low-dose nicardipine $(0.075 \mathrm{mg} / \mathrm{kg} / \mathrm{h})$ treatment is associated with a virtually equivalent benefit in terms of vasospasm prevention but with fewer side effects [49]. Another placebocontrolled double-blind trial has demonstrated that intravenous fasudil, a protein kinase inhibitor, results in a significant reduction in the incidence of angiographic vasospasm, CT hypodensities associated with vasospasm, and symptomatic vasospasm, as well as in the number of patients with a poor clinical outcome associated with vasospasm without any 
serious adverse events [50]. Initial trials with intravenous infusion of magnesium sulfate [51] and endothelin receptor antagonists [52] showed promising results. However, more recent data from larger phase III randomized trials do not support the use of either approach [53, 54]. Statin therapy has been used in many centers; however, the beneficial effect of statins on patients with aneurysmal SAH remains largely controversial [55]. Early clot removal [56], lumbar CSF drainage [57] and cisternal irrigation with vasodilators and/or thrombolytics $[58,59]$ have also been proposed.

\section{Endovascular Therapy in SAH-Induced Cerebral Vasospasm}

Medical treatment is usually the initial step when clinical vasospasm is suspected. It is usually performed by administration of intravenous fluids, albumin, inotropic agents and vasopressors. Unfortunately, however, vasospasm is often refractory to these interventions. Moreover, many patients do not tolerate 'triple- $\mathrm{H}$ ' therapy, usually due to cardiac and pulmonary complications including myocardial ischemia, congestive heart failure and pulmonary edema. For these patients, early endovascular treatment appears to be the best alternative [17, 18, 36, 60-62]. The most common modalities used in the endovascular treatment of cerebral vasospasm are mechanical dilatation with balloon angioplasty, pharmacological dilatation with intra-arterial (IA) drug infusion, or a combination of both.

\section{Percutaneous Transluminal Balloon Angioplasty}

Treatment of vasospastic vessels by percutaneous transluminal balloon angioplasty (PTA) was first introduced in 1984 by Zubkov et al. [63]. The adoption of this technique has steadily increased over the last decades with the advent of improved balloon technology and the growth of interventional neuroradiology as a specialty. Multiple case series have now been published demonstrating the efficacy and safety of balloon angioplasty. Although this treatment modality has never been subjected to controlled randomized trials, the reported neurological improvement rates have been as high as $90 \%$, which is far better than the natural history of the disease.

The effects of transluminal angioplasty on CBF have been studied with xenon-enhanced CT. In this series, all patients had an improvement on CBF after angioplasty, and 92\% demonstrated neurological improvement [64]. Although the ideal timing for the treatment of patients with symptomatic vasospasm still remains a matter of debate, there is a strong indication that the sooner these patients are aggressively treated, the better the chances for improved outcome. Rosenwasser et al. [65] studied 93 patients who underwent endovascular management of clinical vasospasm that was medically refractory. They observed that the group that underwent endovascular management within a 2-hour window after the development of symptoms demonstrated sustained clinical improvement compared with the group treated after a 2-hour window. The authors then concluded that a 2-hour window may exist for restoration of blood flow to ultimately improve a patient's outcome [65].

The exact mechanisms underlying the responses to PTA in humans remain to be fully defined. Indeed, most of the current understanding about the pathophysiology of PTA in cerebral vasospasm is derived from animal models of SAH. Canine models have demonstrated complex morphological changes in the dilated vessels, including: flattening of the endothelial cells; straightening, thinning and occasional rupturing of the internal elastic lamina; and straightening and crowding of smooth muscle cells in the tunica media. In addition, an immediate functional impairment of vascular smooth muscle has been documented via impaired responses to pharmacological agents. These functional and morphological changes are mostly resolved 3 weeks after transluminal balloon angioplasty $[66,67]$. A primate model of experi- 
mental cerebral vasospasm has shown similar morphological changes after PTA, including: endothelium denudation with platelet coverage; stretching and focal dehiscence of internal elastic lamina; and deformed and irregularly arranged myocytes in media [68]. Human postmortem studies after treatment with PTA for aSAH-induced vasospasm have shown compression of the connective tissue, stretching of the internal elastic lamina, and a combination of compression and stretching of the smooth muscle of the dilated arteries [69, 70]. Torn and thinned areas of the wall and intramural hemorrhages have also been documented and were theoretically caused by overinflation [70]. Thus, the main mechanism underlying the long-lasting effects of PTA appears to be related to the stretching and disruption of both the degenerative muscle and the proliferative nonmuscle components, mainly in the media of the vasospastic arteries.

Balloon angioplasty is usually limited to the proximal vessels ( $>2-3 \mathrm{~mm})$, predominantly the supraclinoid internal carotid artery, the M1 and proximal M2 segments of the middle cerebral artery, the A1 segment of the anterior cerebral artery, the P1 segment of the posterior cerebral artery, and the basilar artery. Distal vessel balloon angioplasty is typically not feasible. Vessel tortuosity, averting endovascular navigation, is another potential limitation. The results of balloon angioplasty tend to be more durable than those seen with pharmacological treatment; however, angioplasty is associated with several potential complications such as reperfusion injury, embolism, thrombosis, displacement of surgical clips and vessel rupture. In a review by Hoh and Ogilvy [74], balloon angioplasty had an approximately 5\% risk of major complication, including an approximate $1 \%$ risk of vessel perforation/rupture, which is usually fatal $[17,18,63,71-76]$. Recently, some authors described the occurrence of delayed stenosis after angioplasty $[77,78]$. Although uncommon, recurrence of vasospasm after angioplasty may also occur [79].

Jestaedt et al. [80] studied the efficacy of PTA for the treatment of severe angiographic vasospasm in 38 patients (>70\% vessel narrowing). In their analysis, infarction after PTA occurred in only 4/57 middle cerebral artery territories (7\%) that had been treated with PTA as compared with $23 / 61(38 \%)$ anterior cerebral artery territories not subjected to PTA ( $p<$ 0.001 ). There were 3 procedure-related complications (1 asymptomatic) including 1 dissection and 2 temporary vessel occlusions [80].

Another recent analysis of a prospective database of 75 patients treated with 85 PTA procedures demonstrated favorable safety data with no vessel rupture or perforation. However, thromboembolic complications occurred in $4 / 85$ procedures $(4.7 \%)$. The technical success rate by vessel treated was: distal internal carotid arteries, $100 \%$; proximal middle cerebral arteries, 94\%; vertebral arteries, 73\%; basilar arteries, 88\%; and anterior cerebral arteries, 34\%. Follow-up angiography showed severe recurrent vasospasm in only 15 (13\%) of 116 vessels studied after PTA [79].

The Balloon Prophylaxis of Aneurysmal Vasospasm study [81] was a phase II multicenter, randomized clinical trial comprising 170 Fisher grade III SAH patients who underwent 1:1 randomization to PTA within $96 \mathrm{~h}$ after ictus. Incidence rates of delayed ischemic neurologic deficits were lower in the PTA group, although this did not reach statistical significance $(\mathrm{p}=$ 0.30 ). The authors also claimed that PTA resulted in an absolute risk reduction of $5.9 \%$ and a relative risk reduction of $10.4 \%$ in unfavorable outcomes, but again this was not statistically significant $(\mathrm{p}=0.54)$. The length of stay in intensive care units and hospitals was similar in both groups. Four patients had procedure-related vessel perforations, of which 3 patients died [81].

\section{IA Pharmacological Therapy}

Pharmacological dilatation with IA drug infusion has the advantages of more distal penetration in the cerebral arterial system and a better safety profile. In addition, it is easier to perform, and in many cases drug administration can be performed through a diagnostic 
catheter positioned in the internal carotid or vertebral arteries. Since the final effect of these drugs is vascular relaxation and vasodilatation, hypotension and increase in ICP are important potential drawbacks of this treatment modality. Recurrent vasospasm with the necessity of multiple treatments is another important disadvantage.

We now discuss the rationale, indications and potential complications of endovascular pharmacological treatment of cerebral vasospasm as well as the medications used, their mechanisms of action and the results available in the literature.

Papaverine

IA papaverine infusion was first described as a treatment modality for cerebral vasospasm in 1992 [82, 83]. Papaverine is a benzylisoquinoline alkaloid derived from opium. It is a potent nonselective vasodilator and its effect is believed to result from inhibition of cyclic adenosine monophosphate (cAMP) and cyclic guanosine monophosphate phosphodiesterases in the smooth muscle, as well as from blockage of calcium ion channels in the cell membrane, resulting in vasodilation by inhibition of smooth muscle contraction. The active half-life of papaverine in humans has not been clearly defined; however, in canine vasospasm models it has been shown to be $<1 \mathrm{~h}[18,82-84]$.

Multiple series have suggested that IA papaverine reverses cerebral vasospasm angiographically, on TCD as well as clinically. In this setting, papaverine has also been shown to improve CBF, cerebral circulation time and cerebral oxygenation [8, 10, 17, 18, 72, 82-95]. Kaku et al. [82] performed superselective IA infusion of $0.2 \%$ papaverine hydrochloride in 37 vascular territories of 10 patients with symptomatic vasospasm. Thirty-four of the 37 vascular territories were successfully dilated, and 8/10 patients showed improvement in neurological function after the procedure. There were no serious side effects. Kassell et al. [83] reported a series of 12 patients who were treated with IA papaverine. Eight patients had marked angiographic reversal of the arterial narrowing following papaverine infusion. Four patients showed dramatic reversal of profound neurological deficits. Two patients demonstrated severe recurrent vasospasm. Two patients developed focal neurological deficits during papaverine infusion, which resolved spontaneously over several hours after cessation of the infusion. In a literature review performed by Hoh and Ogilvy [74], transient clinical improvement was found in $43 \%$ of the patients treated. Vajkoczy et al. [8] prospectively studied the regional CBF during and after IA papaverine infusion by quantitative, bedside thermal diffusion flowmetry on 8 patients with vasospasm after aSAH. Reversal of cerebral hypoperfusion was demonstrated; however, it only lasted approximately $3 \mathrm{~h}$. This short-term effect associated with recurrent vasospasm often requires many repeat treatments. Firlik et al. [96] analyzed 15 consecutive patients with aSAH in whom papaverine was employed for the treatment of symptomatic vasospasm. All patients exhibited delayed ischemic neurologic deficits, focal cerebral hypoperfusion on stable xenon-enhanced CT CBF studies, and angiographically defined arterial narrowing. The vessel caliber improved immediately following treatment on 18/23 occasions. The associated clinical improvement was major on 6 occasions, and either minor or nonexistent on 17 . The authors concluded that, although IA papaverine resulted in the reversal of arterial narrowing in the majority of cases (78\%), this angiographic improvement was associated with CBF augmentation in only $46 \%$ of the cases and with major clinical improvement in only $26 \%$ [96]. The concentration of the infusion may also influence its response. Sawada et al. [97] evaluated the effect of intra-arterially infused papaverine solutions of various concentrations on cerebral vasospasm following SAH. In a group of patients who received a $0.4 \%$ (80 mg/20 ml) IA papaverine infusion over a 10-min period, 24 vascular territories (80\%) were successfully dilated and 7 patients (44\%) showed a marked reversal of neurological deficits, suggesting that this was a beneficial regimen. Conversely, transient focal neurological deficits were seen in $44 \%$ of the patients who received a high-concentration (0.8-2\%) IA papaverine infusion [97]. 
Increases in ICP are well reported with IA infusion of papaverine [7, 10, 17, 72, 86, 92]. Sustained ICP elevation following papaverine administration may be associated with poor outcome [7]. This side effect is likely related to increase in CBF and venous capacitance from diffuse vasodilatation. ICP monitoring is therefore recommended. Cross et al. [86] demonstrated that patients with a baseline ICP below $15 \mathrm{~mm} \mathrm{Hg}$ were less likely to have a significant increase in ICP with papaverine treatment. Interestingly, Elsayed et al. [10] reported an increase in intracranial venous diameters following IA papaverine, but it did not correlate with changes in ICP. Other reported complications include cardiac side effects, thrombocytopenia, hypotension, neurological deficits, loss of visual acuity, mydriasis and paradoxical worsening of vasospasm. Papaverine crystals may also precipitate when mixed with contrast or heparin, increasing the risk of distal embolism [84, 85, 87, 92, 98, 99]. Smith et al. [9] published on a series of 5 patients with angiographic vasospasm who experienced sustained neurological deterioration and selective diffusion-weighted MRI changes in the gray matter following chlorobutanol-preserved papaverine infusion. The authors postulate that these changes more likely represent a direct and permanent neurotoxic effect of papaverine than of chlorobutanol. A recent report suggests that papaverine disrupts the blood-brain barrier, resulting in contrast extravasation and possibly facilitating brain damage [100]. With the advent of newer medications, carrying a better side effect profile and presumably improved efficacy, the use of papaverine has largely declined over recent years.

\section{Amrinone}

Amrinone is a cAMP phosphodiesterase-specific inhibitor (phosphodiesterase III isoenzyme) and, as a result, it increases the level of intracellular cAMP. It has positive inotropic and vasodilatory activity, being used for congestive heart failure management. Its IA use for treatment of cerebral vasospasm was reported by Yoshida et al. [13] in 1996. They reported 2 cases of symptomatic vasospasm refractory to IA infusion of papaverine. Both patients had neurological improvement immediately after the procedure. An increase in CBF was demonstrated by xenon CT in both cases. Transient hypotension requiring dopamine infusion occurred in 1 patient.

Milrinone

Milrinone is a bipyridine methyl carbonitrile analog to amrinone with positive inotropic and direct vasodilatory activity. It selectively inhibits cAMP-specific phosphodiesterase III isoenzyme in the cardiac and vascular muscle [14]. Vasodilatation occurs due to an increase in cAMP levels in the smooth muscle, facilitating calcium uptake into the sarcoplasmatic reticulum, reducing the amount of calcium available for contraction and thereby reducing vascular tone [14, 101]. Milrinone has a half-life of approximately $50 \mathrm{~min}$ [14]. It has been used effectively for prevention of chronic cerebral vasospasm in a canine model [102].

Arakawa et al. [14] reviewed 7 patients with symptomatic vasospasm on whom IA and subsequently intravenous administration of milrinone was performed. Milrinone was administered intra-arterially at a concentration of $0.25 \mathrm{mg} / \mathrm{ml}$ and at a rate of $1 \mathrm{ml} / \mathrm{min}$ to a total dose that ranged from 5 to $15 \mathrm{mg}$. An intravenous infusion was then started at 0.5 or $0.75 \mu \mathrm{g} /$ $\mathrm{kg} / \mathrm{min}$ and kept for up to 2 weeks from the onset of SAH. Satisfactory dilatation was achieved in all patients, with a mean increase in vessel diameter of up to $78 \%$. Ipsi- and contralateral increases in CBF were noted. Three patients had recurrent vasospasm despite continuous intravenous milrinone infusion. There was no significant change in blood pressure or heart rate. Neurological improvement was seen in $58.3 \%$ of the patients after treatment [14].

Recently, two studies have also shown that IA milrinone appears to be safe and effective in the treatment of SAH-induced vasospasm [103, 104]. Fraticelli et al. [103] studied the effects of IA milrinone (8-24 mg) followed by intravenous milrinone infusion in 22 patients 


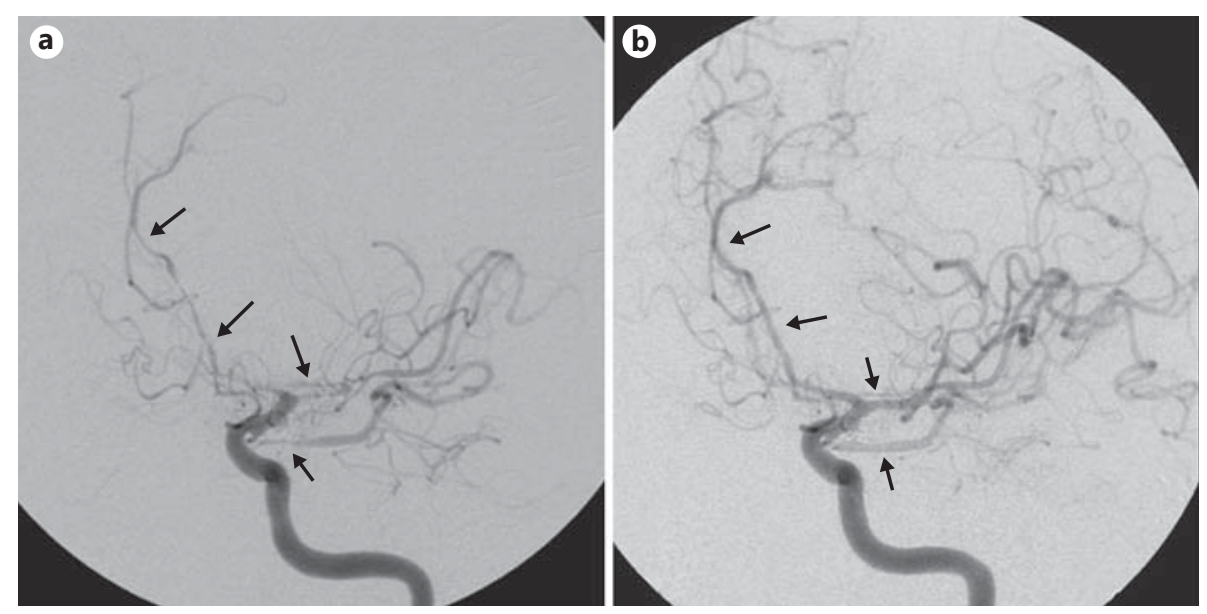

Fig. 1. Angiograms of a 53-year-old gentleman who developed acute neurological symptoms (mental status changes and right hemiparesis) on post-SAH day 6 after a left posterior communicating artery aneurysm rupture. a A left internal carotid artery angiogram was performed, demonstrating severe proximal and distal vasospasm in the middle cerebral, anterior cerebral and posterior communicating arteries (arrows). IA nicardipine infusion was started and $15 \mathrm{mg}$ of nicardipine were administered through the guide catheter. However, the patient developed refractory hypotension and the nicardipine was stopped; $5 \mathrm{mg}$ of milrinone was then infused intra-arterially to complete the treatment. b Posttreatment image demonstrating near-complete reversal of the angiographic vasospasm (arrows).

with cerebral vasospasm. The results showed a significant increase in vessel caliber and moderate increase in heart rate with no significant change in arterial pressure. Further treatment was necessary in 5 patients due to vasospasm recurrence within $48 \mathrm{~h}$ after the initial procedure. Notably, continuous cisternal irrigation of milrinone has also been successfully used in the prevention of aSAH-induced vasospasm [105].

Milrinone has been used in our department to treat patients with poor tolerability to IA nicardipine (fig. 1). We also found that the combination of nicardipine and milrinone is well tolerated and appears to have a synergistic effect, since these medications have different mechanisms of actions [106].

Verapamil

Verapamil is a phenylalkylamine (non-dihydropyridine) calcium channel blocker that acts in the smooth muscle cells reducing the influx of calcium producing vasodilation. It is known to suppress automaticity in the sinoatrial node and conduction in the atrioventricular node. Of note, verapamil also has negative cardiac inotropic effects, which is an untoward effect in patients with cerebral vasospasm $[17,18,44]$.

Low-dose IA verapamil infusion has been successfully used to treat coronary vasospasm refractory to nitroglycerin treatment [107]. Verapamil has also been advocated for the treatment/prevention of mechanically induced vasospasm [11]. Joshi et al. [108] demonstrated that IA administration of verapamil increases CBF as a linear function of cerebral artery pressure. The authors postulated that IA infusion of vasodilators may augment CBF during acute cerebral hypotension. Experiments in animal models suggest that the vasodilatory response to verapamil is dose dependent, stabilizing after 15-30 min [109].

Feng et al. [11] conducted a retrospective review of 34 procedures on 29 patients who received IA verapamil infusion for the treatment of aSAH-induced vasospasm. Verapamil was administered in three settings: (1) before balloon angioplasty to prevent catheter-induced 
vasospasm; (2) for treatment of mild vasospasm; and (3) for treatment of moderate-to-severe vasospasm that could not be treated by angioplasty. In the first two settings, up to $2 \mathrm{mg}$ of verapamil were infused intra-arterially. In the third setting, the patients received higher doses of verapamil. The average dose of verapamil per patient was $3 \mathrm{mg}$. No significant changes in blood pressure or heart rate were observed. The patients showed no signs of increased ICP by hemodynamic parameters, neurologic examination or CT of the head; however, direct ICP monitoring was not performed in this study. Four patients with severe vasospasm received 4-8 mg of verapamil infused through the internal carotid artery over $30 \mathrm{~min}$. These 4 patients did not experience any precipitous changes in hemodynamics or signs of elevated ICP, suggesting that higher doses could be safe. Angiographic assessment of IA verapamil infusion was performed on only 10 occasions and showed an approximately $44 \%$ increase in vessel diameter in the spastic segment. Neurologic improvement was noted after $5 / 17$ procedures when verapamil was used as the sole treatment [11]. Mazumdar et al. [12] studied the change in intracranial arterial diameters following IA verapamil infusion as vasospasm treatment. Eighteen treatments were examined in 15 patients. Baseline arterial measurements were made on each patient's initial angiogram and on the angiogram demonstrating spasm prior to endovascular therapy. The doses of verapamil ranged from 2.5 to $10 \mathrm{mg}$ (mean: $7.4 \mathrm{mg}$ ) and administration time from 5 to $10 \mathrm{~min}$. From the time of the initial angiogram to the time of vasospasm treatment there was a $21.6 \%$ decrease in proximal artery diameter, a $47.1 \%$ decrease in intermediate artery diameter, and a $12.4 \%$ decrease in distal artery diameter. After IA verapamil infusion, the proximal vessels showed a $1.1 \%$ decrease in diameter, the intermediate vessels showed a $9.4 \%$ increase, and the distal vessels showed a 3.3\% decrease. Six of the 15 patients demonstrated neurological improvement within $24 \mathrm{~h}$. There were no significant changes in blood pressure or ICP in relation to the treatment in 14/15 patients. One patient had systemic hypotension that resolved after the verapamil infusion was stopped [12]. Higher doses of verapamil have also been safely used [110,111]. Keuskamp et al. [111] studied 10 patients who underwent 12 procedures in which $20 \mathrm{mg}$ or more of IA verapamil was used, and they demonstrated no statistically significant changes in MAP, ICP or heart rate but significant improvement in the degree of vasospasm. Recently, Albanese et al. [110] reported the use of extremely high doses of IA verapamil (average dose per vessel: $164 \mathrm{mg}$; range of total dose per treatment: 70-720 mg). The results showed that changes in blood pressure and ICP were transient and reversible within minutes after stopping the infusion. It has also been our experience that patients tolerate higher doses of IA verapamil (20-50 mg total dose) with a mild and rapidly reversible decrease in blood pressure and a minimal increase in ICP.

\section{Nimodipine}

Nimodipine is a dihydropyridine calcium channel antagonist that blocks the influx of extracellular calcium into L-type voltage-gated calcium channels. Nimodipine appears to reduce smooth muscle contraction and decrease the release of vasoactive substances from the endothelium and platelets. It is also thought to have neuroprotective effects, preventing calcium overload in ischemic neurons $[4,6,112]$. Potential complications include hypotension, bradycardia, rash and diarrhea. Rare cases of refractory hypotension leading to death have been reported with the intravenous use of nimodipine [113].

Both oral and intravenous nimodipine have been shown to decrease the incidence of cerebral infarction and improve outcomes after aneurysmal and traumatic SAH $[26,61,114$, 115]. An experimental SAH model suggested that IA nimodipine might be more effective than IA papaverine in promoting reversal of vasospasm [5]. Biondi et al. [6] studied the efficacy of IA nimodipine in preventing infarcts in 25 consecutive patients with symptomatic vasospasm. Nimodipine was infused intra-arterially through a diagnostic catheter at a rate of $0.1 \mathrm{mg} / \mathrm{min}$. Overall, 30 procedures were performed with an intraprocedural mean decrease in systolic 
blood pressure of $18 \mathrm{~mm} \mathrm{Hg}$. Postprocedural clinical improvement and favorable outcomes (modified Rankin Scale scores of 0-2) were seen in 76 and $72 \%$ of the patients, respectively [6]. Of note, significant vessel dilatation was observed in only $43 \%$ of the cases, suggesting a possible underlying effect in terms of neuroprotection and/or microcirculation. Hui and Lau [4] studied another 9 patients who received IA nimodipine for cerebral vasospasm treatment. The average dose of nimodipine was $3.3 \mathrm{mg}$ per vessel. The mean increase in diameter of the vasospastic segment was $66.6 \%$. Eight patients had immediate clinical improvement following treatment. Follow-up at 2 months demonstrated that 7 patients had sustained clinical improvement. No significant changes in blood pressure or heart rate were noted. In a recent study by Hänggi et al. [116], 26 patients received doses of IA nimodipine ranging from 0.8 to $3.6 \mathrm{mg}$. No angiographic improvement was seen in 8 patients; 6 patients experienced a transient reversible moderate decrease in blood pressure. There was 1 death $24 \mathrm{~h}$ after the procedure due to an increase in ICP. The pooled results of perfusion for this group of patients showed improved time to peak and mean transit time 1 day after the intervention; however, the results were transient and $61 \%$ of the patients suffered additional infarct.

Nicardipine

Nicardipine is a dihydropyridine calcium antagonist that, similarly to nimodipine, blocks the L-type voltage-gated calcium channels preventing the influx of extracellular calcium, which would eventfully lead to muscle contraction. Nicardipine demonstrates more selectivity for vascular smooth muscle cells than for cardiac muscle. Its half-life is approximately $40 \mathrm{~min}$ [16]. Unlike nimodipine, nicardipine has the advantage of parenteral administration in North America.

Initial dose escalation studies demonstrated that intravenous nicardipine resulted in notable improvement in angiographic and symptomatic vasospasm at a dose of $0.15 \mathrm{mg} / \mathrm{kg} / \mathrm{h}$ [117]. A subsequent, prospective, multicenter, randomized, double-blind, placebo-controlled study was conducted to determine the efficacy of high-dose intravenous nicardipine in the prevention of vasospasm. Results from this and a second study with low-dose intravenous nicardipine $(0.075 \mathrm{mg} / \mathrm{kg} / \mathrm{h})$ demonstrated that the nicardipine-treated groups had a significantly lower incidence of symptomatic, angiographic and TCD vasospasm; however, this did not translate into better outcomes $[48,49,118]$. Furthermore, each of these dosing schedules was limited by prolonged hypotension, pulmonary edema and renal dysfunction.

More recent studies involving surgically implanted prolonged-release nicardipine pellets [119] as well as cisternal [58] nicardipine infusion have shown promising results in the prevention/treatment of SAH-induced vasospasm.

Badjatia et al. [16] reported their prospective experience with IA nicardipine in the treatment of SAH-induced vasospasm. Forty-four vessels were treated in 18 patients. Clinical, angiographic, TCD, blood pressure and ICP data were collected. All vessels treated demonstrated angiographic improvement in the degree of vasospasm. The vessels that were scanned by TCD demonstrated significant decreases in peak systolic velocity after treatment. Neurological improvement was seen in approximately $42 \%$ of the patients after treatment. ICP was transiently elevated in 5 patients and persistently elevated in 1 patient (although this was likely the result of intraparenchymal hemorrhage from external ventricular drain placement). There were no significant changes in blood pressure or signs of pulmonary edema or renal dysfunction. Tejada et al. [120] used IA nicardipine (doses ranging from 10 to $40 \mathrm{mg}$ ) to treat 11 patients (20 cases). The authors noted significant clinical improvement in 10 of the 11 patients. Complications were seen in 4 cases, including thromboembolism in 3 cases. A systolic blood pressure drop of $>21 \%$ was observed in $50 \%$ of the 8 cases for whom the systolic blood pressure was documented. No increase in ICP was noted in this patient population. Linfante et al. [121] demonstrated results of significant improvement in vessel diameter $(p<0.001)$ following IA administration of nicar- 
dipine. The hemodynamic changes were apparently not related to the dose used. No change in ICP was noted.

Hemodynamic changes following IA infusion of nicardipine, including significant decrease in blood pressure and tachycardia, have frequently been seen [120-122]. In cases where hemodynamic instability is a matter of concern, anesthesia support is usually necessary. In our department, nicardipine is the medication of choice for the treatment of vasospasm. We can currently draw on an experience of more than 200 patients treated. In our protocol, nicardipine is mixed with normal sodium chloride solution $(0.9 \% \mathrm{NaCl})$ to a concentration of $0.1 \mathrm{mg} / \mathrm{ml}$ and infused intra-arterially through the diagnostic catheter after selective catheterization of the internal carotid artery or vertebral artery. We reserve microcatheterization for anteriorcirculation cases where there is more selective vasospasm (e.g. severe middle cerebral artery vasospasm without significant involvement of the anterior cerebral arterial vessels and vice versa) or when there is a robust posterior communicating artery. The rationale for this approach is to avoid unnecessary delivery of the drug to an unaffected territory. Total doses of 10-30 mg are commonly used. We typically treat our patients with the support of an anesthesiologist for blood pressure management, and a ventriculostomy catheter is placed in all cases for continuous ICP monitoring and optimization of cerebral perfusion pressure. In our anecdotal experience, we have not had any significant and sustained ICP increases during the procedure. Reflex tachycardia has been seen in some cases. The decrease in systolic blood pressure is usually well controlled with vasopressors and very responsive when the infusion is interrupted. Some patients with refractory hypotension, however, cannot tolerate increases in vasopressor doses. In these cases, the nicardipine infusion is stopped and, if there still is significant vasospasm seen, IA infusion of milrinone is considered. Balloon angioplasty is another option in cases of proximal vasospasm. Even though nicardipine is a safe and effective treatment, vasospasm recurrence requiring further treatment is not uncommon (fig. 2).

To further evaluate the efficacy of this treatment, we performed first-pass quantitative cine-CT perfusion on 6 patients with aSAH and symptomatic vasospasm, immediately prior to and then following IA administration of nicardipine [123]. In 5 of the 6 patients, both CBF $(\mathrm{p}=0.00004)$ and mean transit time (mean decrease: $29 \% ; \mathrm{p}=0.002)$ improved significantly in the affected regions in response to nicardipine therapy. In 1 patient, we were unable to quantify the improvement in flow parameters, due to slice selection differences between the pre- and posttreatment examinations.

Fasudil Hydrochloride

Fasudil hydrochloride [hexahydro-1-(5-isoquinolinesulfonyl)-1H-1,4-diazepine hydrochloride] is a potent vasodilator with relative specificity for the cerebral arteries. In contrast to nimodipine and nicardipine, which are calcium entry blockers, fasudil inhibits the action of the free intracellular calcium ion. Fasudil also inhibits myosin light-chain kinase, the final common pathway of smooth muscle contraction, as well as protein kinase $\mathrm{C}$, which increases blood vessel contraction by activating actin through phosphorylation of calponin. Fasudil and its active metabolite, hydroxyfasudil, effectively inhibit Rho kinase, which has been shown to be involved in the development of cerebral vasospasm [20,21,50]. A significant reduction in angiographic (38 vs. $61 \%$ ) and symptomatic vasospasm ( 35 vs. $50 \%$ ) as well as in CT hypodensities (16 vs. $38 \%$ ) and poor clinical outcome (12 vs. $26 \%$ ) was seen in a prospective doubleblind trial in which 267 patients with aSAH were randomized to receiving intravenous fasudil versus placebo for 14 days following surgical treatment [50].

Tachibana et al. [20] performed a pilot study to evaluate the safety of IA infusion of fasudil in 10 patients with angiographic vasospasm. Three of them were symptomatic. Overall 15 procedures were performed and 24 arterial systems treated. One patient was treated 3 times and 2 patients were treated twice. The maximum dose used per procedure was $60 \mathrm{mg}$. Diffuse dila- 

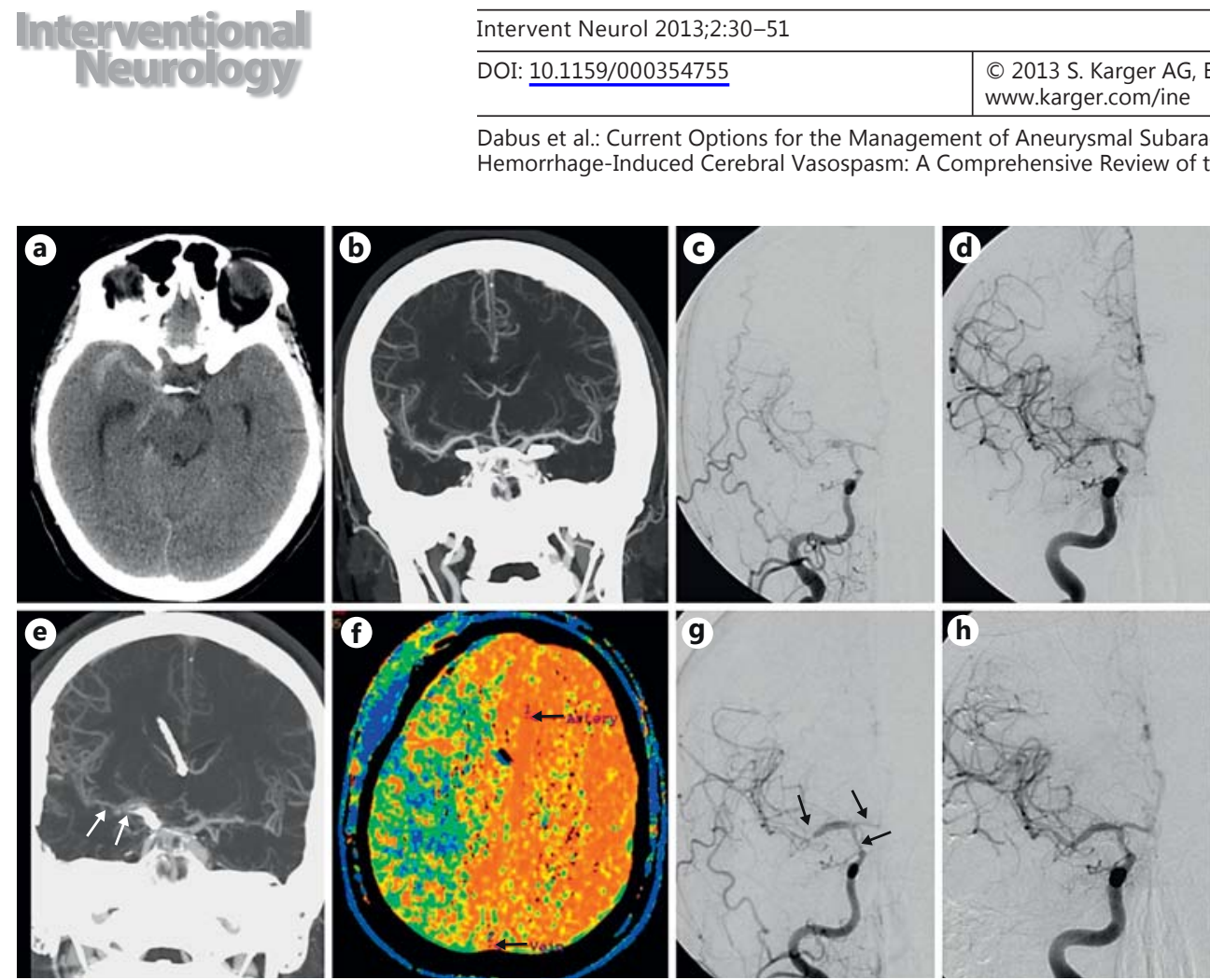

Fig. 2. A 48-year-old lady who presented with Fisher grade III SAH (a). A CT angiogram was also performed, showing the baseline right middle cerebral artery (MCA) caliber (b). The patient developed a very subtle left pronator drift associated with an increase in TCD velocities in the right MCA on post-SAH day 4. A cerebral angiogram was performed, demonstrating severe vasospasm (c). She was treated with IA infusion of $15 \mathrm{mg}$ of nicardipine through the right internal carotid artery, resulting in near-complete reversal of the vasospasm (d). The following day the patient was neurologically intact, but the TCD value was again markedly elevated in the right MCA territory. A CT angiogram and CT perfusion were performed, demonstrating a significant recurrent vasospasm in the right MCA with an increased mean transit time in its territory (e, f). The patient underwent a new angiogram, confirming severe vasospasm (g). She was successfully retreated with nicardipine and milrinone $(\mathbf{h})$. The patient remained asymptomatic in the following days and was discharged with intact neurological and cognitive functions.

tation was seen in almost $60 \%$ of the cases. There was no difference in the degree of dilatation between symptomatic and asymptomatic patients. Two of the 3 symptomatic patients had neurological improvement; however, the third one progressed with a large stroke. There were no embolic complications. The decrease in blood pressure was never greater than $20 \mathrm{~mm} \mathrm{Hg}$.

More recently, Tanaka et al. [21] reported their results on 23 patients that underwent IA fasudil infusion for the treatment of symptomatic vasospasm. Thirty-four procedures were performed. The doses used ranged from 15 to $45 \mathrm{mg}$ (mean: $22.9 \mathrm{mg}$ ). The medication was diluted in $20 \mathrm{ml}$ of saline and infused at a rate of $1.5 \mathrm{mg} / \mathrm{min}$. Angiographic improvement was seen in all cases, but only $11.8 \%$ had complete dilatation. Neurological improvement was seen in $44.1 \%$ of the cases immediately after treatment. At the 3-month follow-up, 15 patients $(65.2 \%)$ had good recovery or moderate disability on the Glasgow Outcome Scale. Six patients had a blood pressure drop of $>20 \mathrm{~mm} \mathrm{Hg}$ and 2 patients developed transient mental status changes after the treatment. Increases in ICP ranging from 1.1 to $5.2 \mathrm{~mm} \mathrm{Hg}$ (mean: $2.4 \mathrm{~mm} \mathrm{Hg}$ ) were also observed. Iwabuchi et al. [124] also demonstrated results with favorable hemodynamic changes after the IA administration of fasudil in 20 patients with angiographic vasospasm after SAH.

Colforsin Daropate Hydrochloride

Colforsin daropate hydrochloride is a water-soluble forskolin derivate that directly activates adenylate cyclase, resulting in elevation of the intracellular concentration of cAMP. It is 
a white crystal that can be dissolved in saline or contrast media and is hard to crystallize. Colforsin has positive chronotropic, inotropic and vasodilatory effects [19].

Suzuki et al. [19] reported the use of IA colforsin daropate to treat 2 patients with symptomatic vasospasm. Three milligrams of colforsin were diluted in $100 \mathrm{ml}$ of normal saline and injected in the internal carotid artery at a rate of $5 \mathrm{ml} / \mathrm{min}$. Both patients demonstrated clinical and angiographic responses. A SPECT study was performed on one of the patients demonstrating increased CBF in the treated territory. More recently, the same group published its experience with IA colforsin in a retrospective study of 29 patients who were also treated with intravenous infusion of fasudil [125]. Angiographic and clinical improvement rates were high (100 and $86 \%$, respectively) in symptomatic patients. Transient changes in heart rate and blood pressure were observed. There was no clinical evidence of increased ICP. Despite good initial response, 16 of the 29 patients required multiple IA treatments.

\section{Novel and Alternative Therapies for SAH-Induced Cerebral Vasospasm}

\section{Flow Augmentation Strategies}

NeuroFlo Catheter

The NeuroFlo device (CoAxia, Maple Grove, Minn., USA) is a dual-balloon catheter uniquely designed to augment CBF via partial occlusion (approx. $70 \%$ ) of the aorta above and below the origin of the renal arteries. This device appears to work through mechanical flow diversion from the high-resistance lower body to the lower-resistance cerebral circulation. Neurohumoral mechanisms may play a role. Lylyk et al. [126] reported on 24 patients with symptomatic vasospasm who were treated with the NeuroFlo device. The authors documented favorable clinical (National Institutes of Health Stroke Scale score drop of $\geq 2$ points in 20/24 patients), TCD (increase in mean flow velocities over 15\%) and angiographic (more robust parenchymal opacification) responses to treatment with a good safety profile [126]. The NeuroFlo catheter has been approved by the FDA for the treatment of SAH-induced cerebral vasospasm. A newer version of the device will allow the coaxial use of a guiding catheter that can be employed to simultaneously deliver IA vasodilators and perform PTA.

BrainsGate

The BrainsGate system consists of an implantable device designed to deliver electrical stimulation to the sphenopalatine ganglion (SPG). The device is inserted into the palatine canal through the greater palatine foramen near the third molar via a relatively simple bedside procedure. The SPG is the source of parasympathetic innervation to most of the anterior portion of the cerebral vasculature. Experimental studies have shown that stimulation of the SPG induces vasodilation of the ipsilateral intradural arteries of the anterior circle of Willis. In addition, SPG stimulation in rats has been shown not only to increase CBF within the normal brain, but also to acutely preserve the diffusion-perfusion mismatch and to reduce infarct size in a rat permanent-suture model [127]. SPG stimulation has also been shown to reverse vasospasm in a canine model of SAH [128]. The safety of this device was established in a pilot trial (ImpACT-1) where 98 patients with acute ischemic stroke underwent SPG stimulation within $24 \mathrm{~h}$ of stroke onset. At this point, the use of the BrainsGate system remains purely investigational and no human use in cerebral vasospasm has yet been reported.

Intra-Aortic Balloon Pump Counterpulsation

The intra-aortic balloon pump has been successfully used to treat patients with symptomatic vasospasm who cannot tolerate or are refractory to 'triple- $H^{\prime}$ therapy [129-132]. In 1 patient, CBF improvement ranging from 33 to 161\% (average: 69.3\%) above the baseline 
could be documented by serial measurements on xenon-enhanced CT [130]. At this point, use of the intra-aortic balloon pump has only been reported in a few small case series and should only be considered for a select group of patients with refractory vasospasm who do not respond to the more traditional therapeutic modalities.

\section{Intrathecal Therapies}

The safety and efficacy of intrathecal nicardipine for the prevention and treatment of SAHinduced vasospasm has been clearly demonstrated in the clinical setting [58, 119, 133-140]. Shibuya et al. [135] reported the effects of prophylactic serial administration of intrathecal nicardipine on vasospasm in 50 Fisher grade III SAH patients. All aneurysms were clipped within 3 days of SAH. Following placement of a cisternal drain, $2 \mathrm{mg}$ of nicardipine was injected 3 times each day for an average of 10 days. The control group consisted of 91 similar patients with cisternal drainage not treated with nicardipine. Intrathecal administration of nicardipine decreased the incidence of symptomatic vasospasm by $26 \%$ and of angiographic vasospasm by $20 \%$, and it increased good clinical outcome 1 month after the hemorrhage by $15 \%$. Postoperative angiograms revealed that patients in the nicardipine group showed less vasospasm of major cerebral arteries near the tip of a drain in the basal cistern, but vasospasm in the A2 and M2 segments was not decreased. Radioisotope cisternography suggested that nicardipine might not reach the subarachnoid space around the A2 and M2 segments. Nine patients complained of headache probably secondary to nicardipine-induced vasodilation. Two patients suffered from meningitis, both were successfully treated. Intrathecal administration of nicardipine through a cisternal catheter was also studied by Susuki et al. [58]. These authors analyzed a consecutive series of 177 patients with SAH (Hunt-Hess grades 1-3; Fisher grade III) who underwent aneurysmal clipping and placement of cisternal drainage within $48 \mathrm{~h}$ of the hemorrhage. Intrathecal administration of $4 \mathrm{mg}$ of nicardipine was performed every $12 \mathrm{~h}$ on postoperative days 3-14. Twenty patients (11.3\%) showed angiographic vasospasm, and 10 of those $(5.7 \%)$ showed symptomatic vasospasm. This reflects an approximately 4- to 6 -fold reduction in the overall incidence of vasospasm. Good outcome defined as good recovery and moderate disability 6 months after onset was seen in $89.2 \%$ of the patients. Thirty-three patients $(18.6 \%)$ required shunt operation and 11 patients $(6.2 \%)$ had intracranial infection. The authors reported that most of the cases of vasospasm happened in peripheral arteries (M2 and A2). They postulated that packed clots in the peripheral CSF space caused this phenomenon and suggest the use of intrathecal fibrinolysis as a possible solution. Kasuya et al. [140] reported that angiographic vasospasm is prevented in arteries with the placement of nicardipine prolonged-release implants at the time of surgery, potentially decreasing the incidence of delayed ischemic neurological deficits. In a series of 97 consecutive patients with SAH who were surgically treated within $72 \mathrm{~h}, 69$ patients were treated with nicardipine prolongedrelease implants and 28 were not. The authors noted that the incidence of delayed ischemic neurological deficits was $6 \%$ in the group treated with nicardipine prolonged-release implants and $11 \%$ in the control group, and that, in their statistical analysis, current smoking $(\mathrm{p}=$ $0.0088)$ and intraventricular hemorrhage on admission CT scans $(p=0.0077)$ were correlated with delayed ischemic neurological deficits [140]. However, the effectiveness of this type of intrathecal administration is limited by rates of diffusion and appears to prevent vasospasm only in the arteries adjacent to the implants. Continuous infusion of intrathecal nicardipine was described by Fujiwara et al. [136]. Five Hunt and Kosnic grade III or IV/Fisher grade III $\mathrm{SAH}$ patients underwent continuous cisternal infusion of nicardipine at a daily dose of $8 \mathrm{mg}$ (12 ml) for 14 days. Postoperative angiography was performed in 3/5 cases 1 week after surgery. No angiographic vasospasm was observed in any of these cases. Symptomatic vasospasm was observed in 1 case of right posterior communicating artery aneurysm as a transient aphasia and right hemiplegia, which recovered within several hours of induced hypervolemia 
and hypertension therapy. One case of mild meningitis was seen at 14 days with improvement within a few days after the cisternal tube had been removed. Three-month outcome was good in all of the 5 cases. Intraventricular nicardipine has also been shown to be associated with a significant and sustained reduction in middle cerebral artery velocity as well as mean CBF velocity as measured by TCD when used in the treatment of cerebral vasospasm following aSAH $[137,139]$.

Studies have shown that cisternal infusion of tissue plasminogen activator or urokinase reduces the incidence of vasospasm in aSAH patients [59, 141-143]. Furthermore, this strategy may facilitate the diffusion of other medications to more distal areas in the subarachnoid space. Sasaki et al. [59] evaluated the effects of cisternal irrigation therapy with urokinase (to dissolve and wash out the subarachnoid clot) and ascorbic acid (to degenerate oxyhemoglobin, one of the strongest spasmogenic substances, into verdoheme-like products, which are nonspasmogenic) in 217 consecutive Fisher grade III SAH patients. All patients underwent surgery within $72 \mathrm{~h}$ from the onset of SAH. Irrigation tubes were then placed in the sylvian fissure (inlet) unilaterally or bilaterally, and in the prepontine or chiasmal cistern (outlet). Lactated Ringer's solution with urokinase $(120 \mathrm{IU} / \mathrm{ml})$ and ascorbic acid $(4 \mathrm{mg} / \mathrm{ml})$ was infused at a rate of $30 \mathrm{ml} / \mathrm{h}$ per side for approximately 10 days. Symptomatic vasospasm was observed in only 6 cases $(2.8 \%), 2$ of which had permanent sequelae $(0.9 \%)$. Complications occurred in only 8 patients. Two patients $(0.9 \%)$ experienced seizures due to occlusion of the drainage tube in the subdural space. Two patients $(0.9 \%)$ developed meningitis with complete recovery after intrathecal antibiotics. Four patients $(1.9 \%)$ had an intracranial hemorrhage likely due to minor local trauma to the brain and small vessels near the irrigation tube. All of these patients recovered without neurological deficits.

Arakawa et al. [105] evaluated the preventive effect of cisternal irrigation with milrinone against vasospasm in 12 high-grade SAH patients (World Federation of Neurosurgeons Scale grade IV or V; Fisher grade III or IV). All aneurysms were clipped or embolized within $72 \mathrm{~h}$ of $\mathrm{SAH}$ onset. Inlet and outlet tubes were placed in the supratentorial cisternal space, lateral ventricle or spinal subarachnoid space. Lactated Ringer's solution containing urokinase (120 $\mathrm{IU} / \mathrm{ml})$, ascorbic acid $(3.5 \mathrm{mg} / \mathrm{ml})$ and milrinone $(3.6 \mu \mathrm{g} / \mathrm{ml})$ was continuously infused at 30 $\mathrm{ml} / \mathrm{h}$ for as long as 2 weeks. Angiographic vasospasm was detected in only 2 of the 11 patients who received milrinone irrigation and underwent postoperative angiography. Vasospasm likely resulted from irrigation obstruction associated with pneumocephalus in one patient and clot in the sylvian fissure in the other patient. The outcome of milrinone irrigation therapy was significantly better than that of conventional therapy.

Lumbar cisternal drainage appears to remove blood from the basal subarachnoid spaces more effectively than an external ventricular drain. In a study comparing patients who received no form of CSF drainage or who were treated solely with an external ventricular drain, patients treated with a lumbar drain had a statistically significant reduction in the incidence of clinical vasospasm (from 51 to 17\%), need for angioplasty (from 45 to 17\%) and occurrence of vasospastic infarction (from 27 to $7 \%$ ). Moreover, these patients were more likely to be discharged home (54 vs. $25 \%$ ) and to have a Glasgow Outcome Scale score of 5 at follow-up (71 vs. 35\%) [57].

\section{Conclusion}

Blood pressure or cardiac output optimization should be the mainstay of hyperdynamic therapy and should be the initial treatment for patients with symptomatic vasospasm. The best approach to treating medically refractory vasospasm has not yet been defined. Endovascular treatment appears to have a positive impact on neurological outcome compared with the 
natural history of the disease. Multiple case reports and case series have been encountered in the literature using many different drug regimens with diverse mechanisms of action. The vast majority of these articles demonstrate that this approach is feasible and safe, and that it appears to have a positive impact on neurological outcome. Intrathecal therapy and flow augmentation strategies in association with medical and endovascular treatment may, in the future, play a role in the management of patients with severe refractory vasospasm. Unfortunately, at this point the lack of prospective randomized controlled studies limits any definite conclusions.

\section{Disclosure Statement}

R.G.N. is a consultant/member of the scientific advisory board for Concentric Medical, ev3 Neurovascular, CoAxia and Rapid Medical. G.D. is a consultant for Covidien Neurovascular, Codman Neurovascular and Reverse Medical.

\section{References}

1 Fisher CM, Kistler JP, Davis JM: Relation of cerebral vasospasm to subarachnoid hemorrhage visualized by computerized tomographic scanning. Neurosurgery 1980;6:1-9.

2 Reilly C, Amidei C, Tolentino J, Jahromi BS, Macdonald RL: Clot volume and clearance rate as independent predictors of vasospasm after aneurysmal subarachnoid hemorrhage. J Neurosurg 2004;101:255-261.

3 Ecker A, Riemenschneider PA: Arteriographic demonstration of spasm of the intracranial arteries, with special reference to saccular arterial aneurysms. J Neurosurg 1951;8:660-667.

- 4 Hui C, Lau KP: Efficacy of intra-arterial nimodipine in the treatment of cerebral vasospasm complicating subarachnoid haemorrhage. Clin Radiol 2005;60:1030-1036.

- 5 Firat MM, Gelebek V, Orer HS, Belen D, Firat AK, Balkanci F: Selective intraarterial nimodipine treatment in an experimental subarachnoid hemorrhage model. AJNR Am J Neuroradiol 2005;26:1357-1362.

6 Biondi A, Ricciardi GK, Puybasset L, Abdennour L, Longo M, Chiras J, van Effenterre R: Intra-arterial nimodipine for the treatment of symptomatic cerebral vasospasm after aneurysmal subarachnoid hemorrhage: preliminary results. AJNR Am J Neuroradiol 2004;25:1067-1076.

- 7 Andaluz N, Tomsick TA, Tew JM Jr, van Loveren HR, Yeh HS, Zuccarello M: Indications for endovascular therapy for refractory vasospasm after aneurysmal subarachnoid hemorrhage: experience at the University of Cincinnati. Surg Neurol 2002;58:131-138, discussion 138.

- 8 Vajkoczy P, Horn P, Bauhuf C, Munch E, Hubner U, Ing D, Thome C, Poeckler-Schoeninger C, Roth H, Schmiedek P: Effect of intra-arterial papaverine on regional cerebral blood flow in hemodynamically relevant cerebral vasospasm. Stroke 2001;32:498-505.

9 Smith WS, Dowd CF, Johnston SC, Ko NU, DeArmond SJ, Dillon WP, Setty D, Lawton MT, Young WL, Higashida RT, Halbach VV: Neurotoxicity of intra-arterial papaverine preserved with chlorobutanol used for the treatment of cerebral vasospasm after aneurysmal subarachnoid hemorrhage. Stroke 2004;35:2518-2522.

10 Elsayed AA, Moran CJ, Cross DT 3rd, Derdeyn CP, Pilgram TK, Milburn JM, Dacey RG Jr, Diringer MN Jr: Effect of intraarterial papaverine and/or angioplasty on the cerebral veins in patients with vasospasm after subarachnoid hemorrhage due to ruptured intracranial aneurysms. Neurosurg Focus 2006;21:E16.

11 Feng L, Fitzsimmons BF, Young WL, Berman MF, Lin E, Aagaard BD, Duong H, Pile-Spellman J: Intraarterially administered verapamil as adjunct therapy for cerebral vasospasm: safety and 2-year experience. AJNR Am J Neuroradiol 2002;23:1284-1290.

12 Mazumdar A, Rivet DJ, Derdeyn CP, Cross DT 3rd, Moran CJ: Effect of intraarterial verapamil on the diameter of vasospastic intracranial arteries in patients with cerebral vasospasm. Neurosurg Focus 2006;21:E15.

13 Yoshida K, Watanabe H, Nakamura S: Intraarterial injection of amrinone for vasospasm induced by subarachnoid hemorrhage. AJNR Am J Neuroradiol 1997;18:492-496.

14 Arakawa Y, Kikuta K, Hojo M, Goto Y, Ishii A, Yamagata S: Milrinone for the treatment of cerebral vasospasm after subarachnoid hemorrhage: report of seven cases. Neurosurgery 2001;48:723-728, discussion 728-730.

15 Barth M, Capelle HH, Weidauer S, Weiss C, Munch E, Thome C, Luecke T, Schmiedek P, Kasuya H, Vajkoczy P: Effect of nicardipine prolonged-release implants on cerebral vasospasm and clinical outcome after severe aneurysmal subarachnoid hemorrhage: a prospective, randomized, double-blind phase IIa study. Stroke 2007;38:330-336.

16 Badjatia N, Topcuoglu MA, Pryor JC, Rabinov JD, Ogilvy CS, Carter BS, Rordorf GA: Preliminary experience with intra-arterial nicardipine as a treatment for cerebral vasospasm. AJNR Am J Neuroradiol 2004;25:819-826.

17 Mindea SA, Yang BP, Bendok BR, Miller JW, Batjer HH: Endovascular treatment strategies for cerebral vasospasm. Neurosurg Focus 2006;21:E13. 
18 Sayama CM, Liu JK, Couldwell WT: Update on endovascular therapies for cerebral vasospasm induced by aneurysmal subarachnoid hemorrhage. Neurosurg Focus 2006;21:E12.

19 Suzuki S, Ito O, Sayama T, Yamaguchi S, Goto K, Sasaki T: Intraarterial injection of colforsin daropate hydrochloride for the treatment of vasospasm after aneurysmal subarachnoid hemorrhage: preliminary report of two cases. Neuroradiology 2006;48:50-53.

20 Tachibana E, Harada T, Shibuya M, Saito K, Takayasu M, Suzuki Y, Yoshida J: Intra-arterial infusion of fasudil hydrochloride for treating vasospasm following subarachnoid haemorrhage. Acta Neurochir (Wien) 1999; 141:13-19.

-21 Tanaka K, Minami H, Kota M, Kuwamura K, Kohmura E: Treatment of cerebral vasospasm with intra-arterial fasudil hydrochloride. Neurosurgery 2005;56:214-223, discussion 214-223.

-22 Weyer GW, Nolan CP, Macdonald RL: Evidence-based cerebral vasospasm management. Neurosurg Focus 2006;21:E8.

23 Baldwin ME, Macdonald RL, Huo D, Novakovic RL, Goldenberg FD, Frank JI, Rosengart AJ: Early vasospasm on admission angiography in patients with aneurysmal subarachnoid hemorrhage is a predictor for in-hospital complications and poor outcome. Stroke 2004;35:2506-2511.

-24 Kassell NF, Sasaki T, Colohan AR, Nazar G: Cerebral vasospasm following aneurysmal subarachnoid hemorrhage. Stroke 1985;16:562-572.

-25 Ohman J, Servo A, Heiskanen 0: Risks factors for cerebral infarction in good-grade patients after aneurysmal subarachnoid hemorrhage and surgery: a prospective study. J Neurosurg 1991;74:14-20.

-26 Treggiari-Venzi MM, Suter PM, Romand JA: Review of medical prevention of vasospasm after aneurysmal subarachnoid hemorrhage: a problem of neurointensive care. Neurosurgery 2001;48:249-261, discussion 261-262.

27 Voldby B, Enevoldsen EM, Jensen FT: Cerebrovascular reactivity in patients with ruptured intracranial aneurysms. J Neurosurg 1985;62:59-67.

28 Yundt KD, Grubb RL Jr, Diringer MN, Powers WJ: Autoregulatory vasodilation of parenchymal vessels is impaired during cerebral vasospasm. J Cereb Blood Flow Metab 1998;18:419-424.

-29 Hop JW, Rinkel GJ, Algra A, Berkelbach van der Sprenkel JW, van Gijn J: Randomized pilot trial of postoperative aspirin in subarachnoid hemorrhage. Neurology 2000;54:872-878.

-30 Mayberg MR, Okada T, Bark DH: Morphologic changes in cerebral arteries after subarachnoid hemorrhage. Neurosurg Clin N Am 1990;1:417-432.

31 Smith RR, Clower BR, Grotendorst GM, Yabuno N, Cruse JM: Arterial wall changes in early human vasospasm. Neurosurgery 1985;16:171-176.

-32 Suzuki S, Suzuki M, Iwabuchi T, Kamata Y: Role of multiple cerebral microthrombosis in symptomatic cerebral vasospasm: with a case report. Neurosurgery 1983;13:199-203.

-33 Dankbaar JW, Slooter AJ, Rinkel GJ, Schaaf IC: Effect of different components of triple-H therapy on cerebral perfusion in patients with aneurysmal subarachnoid haemorrhage: a systematic review. Crit Care 2010;14:R23.

34 Treggiari MM, Deem S: Which H is the most important in triple-H therapy for cerebral vasospasm? Curr Opin Crit Care 2009;15:83-86.

-35 Egge A, Waterloo K, Sjøholm H, Solberg T, Ingebrigtsen T, Romner B: Prophylactic hyperdynamic postoperative fluid therapy after aneurysmal subarachnoid hemorrhage: a clinical, prospective, randomized, controlled study. Neurosurgery 2001;49:593-605, discussion 605-606.

-36 Lennihan L, Mayer SA, Fink ME, Beckford A, Paik MC, Zhang H, Wu YC, Klebanoff LM, Raps EC, Solomon RA: Effect of hypervolemic therapy on cerebral blood flow after subarachnoid hemorrhage: a randomized controlled trial. Stroke 2000;31:383-391.

37 Rinkel GJ, Feigin VL, Algra A, van Gijn J: Circulatory volume expansion therapy for aneurysmal subarachnoid haemorrhage. Cochrane Database Syst Rev 2004;4:CD000483.

-38 Ekelund A, Reinstrup P, Ryding E, Andersson AM, Molund T, Kristiansson KA, Romner B, Brandt L, Säveland $\mathrm{H}$ : Effects of iso- and hypervolemic hemodilution on regional cerebral blood flow and oxygen delivery for patients with vasospasm after aneurysmal subarachnoid hemorrhage. Acta Neurochir (Wien) 2002;144:703712, discussion 712-713.

-39 Naidech AM, Jovanovic B, Wartenberg KE, Parra A, Ostapkovich N, Connolly ES, Mayer SA, Commichau C: Higher hemoglobin is associated with improved outcome after subarachnoid hemorrhage. Crit Care Med 2007;35:2383-2389.

40 Smith MJ, le Roux PD, Elliott JP, Winn HR: Blood transfusion and increased risk for vasospasm and poor outcome after subarachnoid hemorrhage. J Neurosurg 2004;101:1-7.

41 Raabe A, Beck J, Keller M, Vatter H, Zimmermann M, Seifert V: Relative importance of hypertension compared with hypervolemia for increasing cerebral oxygenation in patients with cerebral vasospasm after subarachnoid hemorrhage. J Neurosurg 2005;103:974-981.

42 Muench E, Horn P, Bauhuf C, Roth H, Philipps M, Hermann P, Quintel M, Schmiedek P, Vajkoczy P: Effects of hypervolemia and hypertension on regional cerebral blood flow, intracranial pressure, and brain tissue oxygenation after subarachnoid hemorrhage. Crit Care Med 2007;35:1844-1851, quiz 1852.

43 Macdonald RL, Rosengart A, Huo D, Karrison T: Factors associated with the development of vasospasm after planned surgical treatment of aneurysmal subarachnoid hemorrhage. J Neurosurg 2003;99:644-652. 


\begin{tabular}{l|l}
\hline Intervent Neurol 2013;2:30-51 \\
\hline DOI: $10.1159 / 000354755$ & $\begin{array}{l}\text { @ 2013 S. Karger AG, Basel } \\
\text { www.karger.com/ine }\end{array}$ \\
\hline
\end{tabular}

Dabus et al.: Current Options for the Management of Aneurysmal Subarachnoid

Hemorrhage-Induced Cerebral Vasospasm: A Comprehensive Review of the Literature

-44 Joseph M, Ziadi S, Nates J, Dannenbaum M, Malkoff M: Increases in cardiac output can reverse flow deficits from vasospasm independent of blood pressure: a study using xenon computed tomographic measurement of cerebral blood flow. Neurosurgery 2003;53:1044-1051, discussion 1051-1052.

-45 Kim DH, Haney CL, van Ginhoven G: Reduction of pulmonary edema after SAH with a pulmonary artery catheter-guided hemodynamic management protocol. Neurocrit Care 2005;3:11-15.

-46 Bederson JB, Connolly ES Jr, Batjer HH, Dacey RG, Dion JE, Diringer MN, Duldner JE Jr, Harbaugh RE, Patel AB, Rosenwasser RH, American Heart Association: Guidelines for the management of aneurysmal subarachnoid hemorrhage: a statement for healthcare professionals from a special writing group of the Stroke Council, American Heart Association. Stroke 2009;40:994-1025.

47 Pickard JD, Murray GD, Illingworth R, Shaw MD, Teasdale GM, Foy PM, Humphrey PR, Lang DA, Nelson R, Richards $\mathrm{P}$, et al: Effect of oral nimodipine on cerebral infarction and outcome after subarachnoid haemorrhage: British Aneurysm Nimodipine Trial. BMJ 1989;298:636-642.

48 Haley EC Jr, Kassell NF, Torner JC: A randomized trial of nicardipine in subarachnoid hemorrhage: angiographic and transcranial Doppler ultrasound results - a report of the Cooperative Aneurysm Study. J Neurosurg 1993; 78:548-553.

49 Haley EC Jr, Kassell NF, Torner JC: A randomized controlled trial of high-dose intravenous nicardipine in aneurysmal subarachnoid hemorrhage: a report of the Cooperative Aneurysm Study. J Neurosurg 1993;78:537547.

50 Shibuya M, Suzuki Y, Sugita K, Saito I, Sasaki T, Takakura K, Nagata I, Kikuchi H, Takemae T, Hidaka H, et al: Effect of AT877 on cerebral vasospasm after aneurysmal subarachnoid hemorrhage: results of a prospective placebo-controlled double-blind trial. J Neurosurg 1992;76:571-577.

51 van den Bergh WM, Algra A, van Kooten F, Dirven CM, van Gijn J, Vermeulen M, Rinkel GJ: Magnesium sulfate in aneurysmal subarachnoid hemorrhage: a randomized controlled trial. Stroke 2005;36:1011-1015.

52 Vajkoczy P, Meyer B, Weidauer S, Raabe A, Thome C, Ringel F, Breu V, Schmiedek P: Clazosentan (AXV-034343), a selective endothelin a receptor antagonist, in the prevention of cerebral vasospasm following severe aneurysmal subarachnoid hemorrhage: results of a randomized, double-blind, placebo-controlled, multicenter phase IIa study. J Neurosurg 2005;103:9-17.

53 Dorhout Mees SM, Algra A, Vandertop WP, van Kooten F, Kuijsten HA, Boiten J, van Oostenbrugge RJ, Al-Shahi Salman R, Lavados PM, Rinkel GJ, van den Bergh WM, MASH-2 Study Group: Magnesium for Aneurysmal Subarachnoid Haemorrhage (MASH-2): a randomised placebo-controlled trial. Lancet 2012;380:44-49.

54 Macdonald RL, Higashida RT, Keller E, Mayer SA, Molyneux A, Raabe A, Vajkoczy P, Wanke I, Bach D, Frey A, Marr A, Roux S, Kassell N: Clazosentan, an endothelin receptor antagonist, in patients with aneurysmal subarachnoid haemorrhage undergoing surgical clipping: a randomised, double-blind, placebo-controlled phase 3 trial (CONSCIOUS-2). Lancet Neurol 2011;10:618-625.

-55 Vergouwen MD, de Haan RJ, Vermeulen M, Roos YB: Effect of statin treatment on vasospasm, delayed cerebral ischemia, and functional outcome in patients with aneurysmal subarachnoid hemorrhage: a systematic review and meta-analysis update. Stroke 2010;41:e47-e52.

56 Handa Y, Weir BK, Nosko M, Mosewich R, Tsuji T, Grace M: The effect of timing of clot removal on chronic vasospasm in a primate model. J Neurosurg 1987;67:558-564.

57 Klimo P Jr, Kestle JR, MacDonald JD, Schmidt RH: Marked reduction of cerebral vasospasm with lumbar drainage of cerebrospinal fluid after subarachnoid hemorrhage. J Neurosurg 2004;100:215-224.

58 Suzuki M, Doi M, Otawara Y, Ogasawara K, Ogawa A: Intrathecal administration of nicardipine hydrochloride to prevent vasospasm in patients with subarachnoid hemorrhage. Neurosurg Rev 2001;24:180-184.

59 Sasaki T, Kodama N, Kawakami M, Sato M, Asari J, Sakurai Y, Watanabe K, Onuma T, Matsuda T: Urokinase cisternal irrigation therapy for prevention of symptomatic vasospasm after aneurysmal subarachnoid hemorrhage: a study of urokinase concentration and the fibrinolytic system. Stroke 2000;31:1256-1262.

60 Awad IA, Carter LP, Spetzler RF, Medina M, Williams FC Jr: Clinical vasospasm after subarachnoid hemorrhage: response to hypervolemic hemodilution and arterial hypertension. Stroke 1987;18:365-372.

-61 Feigin VL, Rinkel GJ, Algra A, Vermeulen M, van Gijn J: Calcium antagonists in patients with aneurysmal subarachnoid hemorrhage: a systematic review. Neurology 1998;50:876-883.

62 Suarez JI, Tarr RW, Selman WR: Aneurysmal subarachnoid hemorrhage. N Engl J Med 2006;354:387-396.

63 Zubkov YN, Nikiforov BM, Shustin VA: Balloon catheter technique for dilatation of constricted cerebral arteries after aneurysmal SAH. Acta Neurochir (Wien) 1984;70:65-79.

64 Firlik AD, Kaufmann AM, Jungreis CA, Yonas H: Effect of transluminal angioplasty on cerebral blood flow in the management of symptomatic vasospasm following aneurysmal subarachnoid hemorrhage. J Neurosurg 1997; 86:830-839.

65 Rosenwasser RH, Armonda RA, Thomas JE, Benitez RP, Gannon PM, Harrop J: Therapeutic modalities for the management of cerebral vasospasm: timing of endovascular options. Neurosurgery 1999;44:975-979, discussion 979-980.

66 Megyesi JF, Findlay JM, Vollrath B, Cook DA, Chen MH: In vivo angioplasty prevents the development of vasospasm in canine carotid arteries: pharmacological and morphological analyses. Stroke 1997;28:1216-1224.

67 Megyesi JF, Vollrath B, Cook DA, Chen MH, Findlay JM: Long-term effects of in vivo angioplasty in normal and vasospastic canine carotid arteries: pharmacological and morphological analyses. J Neurosurg 1999;91:100108. 
68 Ohkawa M, Fujiwara N, Tanabe M, Takashima H, Satoh K, Kojima K, Irie K, Honjo Y, Nagao S: Cerebral vasospastic vessels: histologic changes after percutaneous transluminal angioplasty. Radiology 1996;198:179-184.

69 Zubkov AY, Lewis AI, Scalzo D, Bernanke DH, Harkey HL: Morphological changes after percutaneous transluminal angioplasty. Surg Neurol 1999;51:399-403.

70 Honma Y, Fujiwara T, Irie K, Ohkawa M, Nagao S: Morphological changes in human cerebral arteries after percutaneous transluminal angioplasty for vasospasm caused by subarachnoid hemorrhage. Neurosurgery 1995;36:1073-1080, discussion 1080-1081.

71 Bejjani GK, Bank WO, Olan WJ, Sekhar LN: The efficacy and safety of angioplasty for cerebral vasospasm after subarachnoid hemorrhage. Neurosurgery 1998;42:979-986, discussion 986-987.

-72 Elliott JP, Newell DW, Lam DJ, Eskridge JM, Douville CM, le Roux PD, Lewis DH, Mayberg MR, Grady MS, Winn HR: Comparison of balloon angioplasty and papaverine infusion for the treatment of vasospasm following aneurysmal subarachnoid hemorrhage. J Neurosurg 1998;88:277-284.

-73 Eskridge JM, McAuliffe W, Song JK, Deliganis AV, Newell DW, Lewis DH, Mayberg MR, Winn HR: Balloon angioplasty for the treatment of vasospasm: results of first 50 cases. Neurosurgery 1998;42:510-516, discussion 516-517.

74 Hoh BL, Ogilvy CS: Endovascular treatment of cerebral vasospasm: transluminal balloon angioplasty, intraarterial papaverine, and intra-arterial nicardipine. Neurosurg Clin N Am 2005;16:501-516, vi.

75 Murai Y, Kominami S, Kobayashi S, Mizunari T, Teramoto A: The long-term effects of transluminal balloon angioplasty for vasospasms after subarachnoid hemorrhage: analyses of cerebral blood flow and reactivity. Surg Neurol 2005;64:122-126, discussion 127.

76 Newell DW, Eskridge JM, Mayberg MR, Grady MS, Winn HR: Angioplasty for the treatment of symptomatic vasospasm following subarachnoid hemorrhage. J Neurosurg 1989;71:654-660.

77 Merchant A, Drazin D, Dalfino J, Yamamoto J, Boulos AS: Delayed stenosis as a consequence of angioplasty for subarachnoid hemorrhage-induced vasospasm: case report. Neurosurg Focus 2009;26:E23.

78 Sedat J, Chau Y, Popolo M, Gindre S, Rami L, Orban JC: Restenosis after balloon angioplasty for cerebral vasospasm. Cardiovasc Intervent Radiol 2009;32:337-340.

79 Terry A, Zipfel G, Milner E, Cross DT, Moran CJ, Diringer MN, Dacey RG, Derdeyn CP: Safety and technical efficacy of over-the-wire balloons for the treatment of subarachnoid hemorrhage-induced cerebral vasospasm. Neurosurg Focus 2006;21:E14.

-80 Jestaedt L, Pham M, Bartsch AJ, Kunze E, Roosen K, Solymosi L, Bendszus M: The impact of balloon angioplasty on the evolution of vasospasm-related infarction after aneurysmal subarachnoid hemorrhage. Neurosurgery 2008;62:610-617, discussion 610-617.

81 Zwienenberg-Lee M, Hartman J, Rudisill N, Madden LK, Smith K, Eskridge J, Newell D, Verweij B, Bullock MR, Baker A, Coplin W, Mericle R, Dai J, Rocke D, Muizelaar JP, Group BPfAVBS: Effect of prophylactic transluminal balloon angioplasty on cerebral vasospasm and outcome in patients with Fisher grade III subarachnoid hemorrhage: results of a phase II multicenter, randomized, clinical trial. Stroke 2008;39:1759-1765.

82 Kaku Y, Yonekawa Y, Tsukahara T, Kazekawa K: Superselective intra-arterial infusion of papaverine for the treatment of cerebral vasospasm after subarachnoid hemorrhage. J Neurosurg 1992;77:842-847.

83 Kassell NF, Helm G, Simmons N, Phillips CD, Cail WS: Treatment of cerebral vasospasm with intra-arterial papaverine. J Neurosurg 1992;77:848-852.

$84 \mathrm{Liu}$ JK, Couldwell WT: Intra-arterial papaverine infusions for the treatment of cerebral vasospasm induced by aneurysmal subarachnoid hemorrhage. Neurocrit Care 2005;2:124-132.

85 Clouston JE, Numaguchi Y, Zoarski GH, Aldrich EF, Simard JM, Zitnay KM: Intraarterial papaverine infusion for cerebral vasospasm after subarachnoid hemorrhage. AJNR Am J Neuroradiol 1995;16:27-38.

86 Cross DT 3rd, Moran CJ, Angtuaco EE, Milburn JM, Diringer MN, Dacey RG Jr: Intracranial pressure monitoring during intraarterial papaverine infusion for cerebral vasospasm. AJNR Am J Neuroradiol 1998;19:1319-1323.

87 Milburn JM, Moran CJ, Cross DT 3rd, Diringer MN, Pilgram TK, Dacey RG Jr: Increase in diameters of vasospastic intracranial arteries by intraarterial papaverine administration. J Neurosurg 1998;88:38-42.

88 Fandino J, Kaku Y, Schuknecht B, Valavanis A, Yonekawa Y: Improvement of cerebral oxygenation patterns and metabolic validation of superselective intraarterial infusion of papaverine for the treatment of cerebral vasospasm. J Neurosurg 1998;89:93-100.

89 Liu JK, Tenner MS, Gottfried ON, Stevens EA, Rosenow JM, Madan N, MacDonald JD, Kestle JR, Couldwell WT: Efficacy of multiple intraarterial papaverine infusions for improvement in cerebral circulation time in patients with recurrent cerebral vasospasm. J Neurosurg 2004;100:414-421.

90 Livingston K, Guterman LR, Hopkins LN: Intraarterial papaverine as an adjunct to transluminal angioplasty for vasospasm induced by subarachnoid hemorrhage. AJNR Am J Neuroradiol 1993;14:346-347.

91 Marks MP, Steinberg GK, Lane B: Intraarterial papaverine for the treatment of vasospasm. AJNR Am J Neuroradiol 1993;14:822-826.

92 McAuliffe W, Townsend M, Eskridge JM, Newell DW, Grady MS, Winn HR: Intracranial pressure changes induced during papaverine infusion for treatment of vasospasm. J Neurosurg 1995;83:430-434.

93 Milburn JM, Moran CJ, Cross DT 3rd, Diringer MN, Pilgram TK, Dacey RG Jr: Effect of intraarterial papaverine on cerebral circulation time. AJNR Am J Neuroradiol 1997;18:1081-1085.

94 Oskouian RJ Jr, Martin NA, Lee JH, Glenn TC, Guthrie D, Gonzalez NR, Afari A, Vinuela F: Multimodal quantitation of the effects of endovascular therapy for vasospasm on cerebral blood flow, transcranial Doppler ultrasonographic velocities, and cerebral artery diameters. Neurosurgery 2002;51:30-41, discussion 41-43. 
95 Polin RS, Hansen CA, German P, Chadduck JB, Kassell NF: Intra-arterially administered papaverine for the treatment of symptomatic cerebral vasospasm. Neurosurgery 1998;42:1256-1264, discussion 1264-1267.

96 Firlik KS, Kaufmann AM, Firlik AD, Jungreis CA, Yonas H: Intra-arterial papaverine for the treatment of cerebral vasospasm following aneurysmal subarachnoid hemorrhage. Surg Neurol 1999;51:66-74.

97 Sawada M, Hashimoto N, Tsukahara T, Nishi S, Kaku Y, Yoshimura S: Effectiveness of intra-arterially infused papaverine solutions of various concentrations for the treatment of cerebral vasospasm. Acta Neurochir (Wien) 1997;139:706-711.

98 Barr JD, Mathis JM, Horton JA: Transient severe brain stem depression during intraarterial papaverine infusion for cerebral vasospasm. AJNR Am J Neuroradiol 1994;15:719-723.

99 Tsurushima H, Kamezaki T, Nagatomo Y, Hyodo A, Nose T: Complications associated with intraarterial administration of papaverine for vasospasm following subarachnoid hemorrhage: two case reports. Neurol Med Chir (Tokyo) 2000;40:112-115.

100 Platz J, Barath K, Keller E, Valavanis A: Disruption of the blood-brain barrier by intra-arterial administration of papaverine: a technical note. Neuroradiology 2008;50:1035-1039.

101 Honerjäger P: Pharmacology of bipyridine phosphodiesterase III inhibitors. Am Heart J 1991;121:1939-1944.

102 Khajavi K, Ayzman I, Shearer D, Jones SC, Levy JH, Prayson RA, Skibinski CI, Hahn JF, Chyatte D: Prevention of chronic cerebral vasospasm in dogs with milrinone. Neurosurgery 1997;40:354-362, discussion 362-363.

103 Fraticelli AT, Cholley BP, Losser MR, Saint Maurice JP, Payen D: Milrinone for the treatment of cerebral vasospasm after aneurysmal subarachnoid hemorrhage. Stroke 2008;39:893-898.

104 Romero CM, Morales D, Reccius A, Mena F, Prieto J, Bustos P, Larrondo J, Castro J: Milrinone as a rescue therapy for symptomatic refractory cerebral vasospasm in aneurysmal subarachnoid hemorrhage. Neurocrit Care 2009;11:165-171.

105 Arakawa Y, Kikuta K, Hojo M, Goto Y, Yamagata S, Nozaki K, Hashimoto N: Milrinone reduces cerebral vasospasm after subarachnoid hemorrhage of WFNS grade IV or V. Neurol Med Chir (Tokyo) 2004;44:393-400, discussion 401.

106 Nogueira RG, Buonanno FS, Eskey CE, Rabinov JD, Hirsch JA, Pryor JC: Synergistic effect of intra-arterial milrinone and nicardipine on cerebral vasospasm (poster presentation). 9th Joint Annu Meet AANS/CNS Sect Cerebrovasc Surg and Am Soc Intervent Ther Neuroradiol, Orlando, FL, February 2006.

107 Babbitt DG, Perry JM, Forman MB: Intracoronary verapamil for reversal of refractory coronary vasospasm during percutaneous transluminal coronary angioplasty. J Am Coll Cardiol 1988;12:1377-1381.

108 Joshi S, Young WL, Pile-Spellman J, Duong DH, Hacein-Bey L, Vang MC, Marshall RS, Ostapkovich N, Jackson T: Manipulation of cerebrovascular resistance during internal carotid artery occlusion by intraarterial verapamil. Anesth Analg 1997;85:753-759.

109 Shimizu K, Ohta T, Toda N: Evidence for greater susceptibility of isolated dog cerebral arteries to Ca antagonists than peripheral arteries. Stroke 1980;11:261-266.

110 Albanese E, Russo A, Quiroga M, Willis RN, Mericle RA, Ulm AJ: Ultrahigh-dose intraarterial infusion of verapamil through an indwelling microcatheter for medically refractory severe vasospasm: initial experience. J Neurosurg 2010;113:913-922.

111 Keuskamp J, Murali R, Chao KH: High-dose intraarterial verapamil in the treatment of cerebral vasospasm after aneurysmal subarachnoid hemorrhage. J Neurosurg 2008;108:458-463.

112 Findlay JM, Macdonald RL, Weir BK: Current concepts of pathophysiology and management of cerebral vasospasm following aneurysmal subarachnoid hemorrhage. Cerebrovasc Brain Metab Rev 1991;3:336-361.

113 Bayer HealthCare: Important drug warning, February 2006.

114 Conti A, Angileri FF, Longo M, Pitrone A, Granata F, la Rosa G: Intra-arterial nimodipine to treat symptomatic cerebral vasospasm following traumatic subarachnoid haemorrhage: technical case report. Acta Neurochir (Wien) 2008;150:1197-1202, discussion 1202.

115 Kim JH, Park IS, Park KB, Kang DH, Hwang SH: Intraarterial nimodipine infusion to treat symptomatic cerebral vasospasm after aneurysmal subarachnoid hemorrhage. J Korean Neurosurg Soc 2009;46:239-244.

116 Hänggi D, Turowski B, Beseoglu K, Yong M, Steiger HJ: Intra-arterial nimodipine for severe cerebral vasospasm after aneurysmal subarachnoid hemorrhage: influence on clinical course and cerebral perfusion. AJNR Am J Neuroradiol 2008;29:1053-1060.

117 Flamm ES, Adams HP Jr, Beck DW, Pinto RS, Marler JR, Walker MD, Godersky JC, Loftus CM, Biller J, Boarini DJ, et al: Dose-escalation study of intravenous nicardipine in patients with aneurysmal subarachnoid hemorrhage. J Neurosurg 1988;68:393-400.

118 Haley EC Jr, Kassell NF, Torner JC, Truskowski LL, Germanson TP: A randomized trial of two doses of nicardipine in aneurysmal subarachnoid hemorrhage: a report of the cooperative aneurysm study. J Neurosurg 1994;80:788-796.

119 Kasuya H, Onda H, Takeshita M, Okada Y, Hori T: Efficacy and safety of nicardipine prolonged-release implants for preventing vasospasm in humans. Stroke 2002;33:1011-1015.

120 Tejada JG, Taylor RA, Ugurel MS, Hayakawa M, Lee SK, Chaloupka JC: Safety and feasibility of intra-arterial nicardipine for the treatment of subarachnoid hemorrhage-associated vasospasm: initial clinical experience with high-dose infusions. AJNR Am J Neuroradiol 2007;28:844-848.

121 Linfante I, Delgado-Mederos R, Andreone V, Gounis M, Hendricks L, Wakhloo AK: Angiographic and hemodynamic effect of high concentration of intra-arterial nicardipine in cerebral vasospasm. Neurosurgery 2008;63: 1080-1086, discussion 1086-1087. 
122 Avitsian R, Fiorella D, Soliman MM, Mascha E: Anesthetic considerations of selective intra-arterial nicardipine injection for intracranial vasospasm: a case series. J Neurosurg Anesthesiol 2007;19:125-129.

-123 Nogueira RG, Lev MH, Roccatagliata L, Hirsch JA, Gonzalez RG, Ogilvy CS, Halpern EF, Rordorf GA, Rabinov JD, Pryor JC: Intra-arterial nicardipine infusion improves CT perfusion-measured cerebral blood flow in patients with subarachnoid hemorrhage-induced vasospasm. AJNR Am J Neuroradiol 2009;30:160-164.

124 Iwabuchi S, Yokouchi T, Hayashi M, Uehara H, Ueda M, Samejima H: Intra-arterial administration of fasudil hydrochloride for vasospasm following subarachnoid hemorrhage: analysis of time-density curve with digital subtraction angiography. Neurol Med Chir (Tokyo) 2006;46:535-539, discussion 540.

125 Suzuki S, Ito 0, Sayama T, Goto K: Intra-arterial colforsin daropate for the treatment of cerebral vasospasm after aneurysmal subarachnoid hemorrhage. Neuroradiology 2010;52:837-845.

126 Lylyk P, Vila JF, Miranda C, Ferrario A, Romero R, Cohen JE: Partial aortic obstruction improves cerebral perfusion and clinical symptoms in patients with symptomatic vasospasm. Neurol Res 2005;27(suppl 1):S129-S135.

127 Henninger N, Fisher M: Stimulating circle of Willis nerve fibers preserves the diffusion-perfusion mismatch in experimental stroke. Stroke 2007;38:2779-2786.

128 Yarnitsky D, Lorian A, Shalev A, Zhang ZD, Takahashi M, Agbaje-Williams M, Macdonald RL: Reversal of cerebral vasospasm by sphenopalatine ganglion stimulation in a dog model of subarachnoid hemorrhage. Surg Neurol 2005;64:5-11, discussion 11.

129 Apostolides PJ, Greene KA, Zabramski JM, Fitzgerald JW, Spetzler RF: Intra-aortic balloon pump counterpulsation in the management of concomitant cerebral vasospasm and cardiac failure after subarachnoid hemorrhage: technical case report. Neurosurgery 1996;38:1056-1059, discussion 1059-1060.

130 Nussbaum ES, Sebring LA, Ganz WF, Madison MT: Intra-aortic balloon counterpulsation augments cerebral blood flow in the patient with cerebral vasospasm: a xenon-enhanced computed tomography study. Neurosurgery 1998;42:206-213, discussion 213-214.

131 Sato K, Tokairin H, Kato M: Two patients treated with intra-aortic balloon pump counterpulsation after subarachnoid hemorrhage (in Japanese). Masui 2001;50:859-862.

132 Taccone FS, Lubicz B, Piagnerelli M, van Nuffelen M, Vincent JL, de Backer D: Cardiogenic shock with stunned myocardium during triple-H therapy treated with intra-aortic balloon pump counterpulsation. Neurocrit Care 2009;10:76-82.

133 Oki S, Kobayashi M, Yoshihara T, Yamada K, Sakoda K, Uozumi T: Effect of cisternal administration of nicardipine hydrochloride on cerebral vasospasm: a preliminary report. Hiroshima J Med Sci 1987;36:75-79.

134 Toyota A, Nishizawa Y: Cerebral vasospasm after subarachnoid hemorrhage, and inhibitory effect of nicardipine investigated by means of transcranial Doppler ultrasonography (in Japanese). No Shinkei Geka 1991; 19:1143-1150.

135 Shibuya M, Suzuki Y, Enomoto H, Okada T, Ogura K, Sugita K: Effects of prophylactic intrathecal administrations of nicardipine on vasospasm in patients with severe aneurysmal subarachnoid haemorrhage. Acta Neurochir (Wien) 1994;131:19-25.

136 Fujiwara K, Mikawa S, Ebina T: Continuous intrathecal administration of nicardipine using a portable infusion pump system for management of vasospasm after subarachnoid hemorrhage (in Japanese). No Shinkei Geka 2001;29:23-30.

137 Webb A, Kolenda J, Martin K, Wright W, Samuels O: The effect of intraventricular administration of nicardipine on mean cerebral blood flow velocity measured by transcranial Doppler in the treatment of vasospasm following aneurysmal subarachnoid hemorrhage. Neurocrit Care 2010;12:159-164.

138 Goodson K, Lapointe M, Monroe T, Chalela JA: Intraventricular nicardipine for refractory cerebral vasospasm after subarachnoid hemorrhage. Neurocrit Care 2008;8:247-252.

139 Ehtisham A, Taylor S, Bayless L, Samuels OB, Klein MW, Janzen JM: Use of intrathecal nicardipine for aneurysmal subarachnoid hemorrhage-induced cerebral vasospasm. South Med J 2009;102:150-153.

140 Kasuya H, Onda H, Sasahara A, Takeshita M, Hori T: Application of nicardipine prolonged-release implants: analysis of 97 consecutive patients with acute subarachnoid hemorrhage. Neurosurgery 2005;56:895-902, discussion 895-902.

141 Yoshida Y, Ueki S, Takahashi A, Takagi H, Torigoe H, Kudo S: Intrathecal irrigation with urokinase in ruptured cerebral aneurysm cases: basic study and clinical application (in Japanese). Neurol Med Chir (Tokyo) 1985; 25:989-997.

142 Usui M, Saito N, Hoya K, Todo T: Vasospasm prevention with postoperative intrathecal thrombolytic therapy: a retrospective comparison of urokinase, tissue plasminogen activator, and cisternal drainage alone. Neurosurgery 1994;34:235-244, discussion 244-245.

143 Amin-Hanjani S, Ogilvy CS, Barker FG: Does intracisternal thrombolysis prevent vasospasm after aneurysmal

subarachnoid hemorrhage? A meta-analysis. Neurosurgery 2004;54:326-334, discussion 334-335. 